\title{
Effect of Synthesis Parameters on Photoactivity of CdS Nanoparticles
}

\author{
MAHENDRASINGH J. PAWAR ${ }^{*}$, ARCHANA D. INGLE and RAHUL K. TAYAWADE \\ Laboratory of Materials Synthesis, Department of Chemistry, ACS College, \\ Kiran Nagar, Amravati- 444606, M.S., India \\ mjpawar09@outlook.com
}

Received 24 May 2018 / Accepted 3 July 2018

\begin{abstract}
In the present work, CdS nanoparticles were synthesized by four different routes using ammonium sulphide $\left(\left(\mathrm{NH}_{4}\right)_{2} \mathrm{~S}\right)$ as source of (Sulphide) $\mathrm{S}^{2-}$ ions. $\mathrm{CdS}$ nanoparticles were grown by simple chemical precipitation reactions in aqueous medium at room temperature. The effect of stabilizers on the stability and size of CdS nanoparticles was studied. The effect of different reaction parameters on the size of nanoparticles, absorbance and respective band gaps and crystalline structure were studied. The microstructure and morphology of the synthesized CdS nanoparticles have been characterized by x-ray diffraction (XRD), scanning electron microscopy (SEM) and transmission electron microscopy (TEM) analysis. XRD pattern reveals that as-synthesized CdS nanoparticles exhibit both hexagonal and cubic phases. The size of the particles calculated by Debye Scherrer formula according to the XRD spectra has been found to be about 3-30 nm. The optical properties of the sample have been studied by UV-Visible and photoluminescence spectroscopy. The existence of blue shift in UV-Visible spectroscopy reveals the quantum confinement effect of $\mathrm{CdS}$ nanoparticles. Finally, the synthesized CdS nanoparticles were exploited for the degradation of acid blue-29 (AB-29), under UV light. The photocatalytic efficiency of the synthesized nanoparticles, using different reaction routes were compared and optimized.
\end{abstract}

Keywords: CdS Nanoparticles, Acid blue- 29 dye, Photoactivity, Photodegradation of dye

\section{Introduction}

The novel properties viz., enhanced light absorption, quantum confinement, high specific surface area and tunable surfaceto-volume ratio, hierarchical porous structure, etc., of nanostructured photocatalytic materials create tremendous opportunities in extending their applications invarious fields including water and air purification, photocatalytic disinfection, photocatalytic hydrogen generation and dye-sensitized solar cells ${ }^{1-4}$. However, the photocatalytic activity of these materials is still far from that required by commercial applications and therefore further studies are needed in this direction. Many fundamentally physical and chemical properties of photocatalytic materials depend strongly on the size and shape of these materials. Hence, much attention has been paid to explore simple synthetic methods for their synthesis and to understand their distinctive properties as well as to exploit potentially new applications. 
II-VI semiconductor nanoparticles are successfully utilized in photocatalytic applications. CdS is one of the most important II-VI group semiconductors; the band gap is $\sim 2.4 \mathrm{eV}$, having vital applications in photocatalytic applications. Usually, CdSs are of cubic phase and hexagonal phase and the cubic phase can transform into hexagonalat certain temperatures ${ }^{5}$. The hexagonal CdS nanoparticles synthesized via solvothermal method have much better photocatalytic activity for degradation of methylene blue and better hydrogen production activity for water photolysis, using thiourea and cadmium acetate as rawmaterials ${ }^{6,7}$. Jing and Guo reported a CdS catalyst systemwith a high hydrogen production activity for water photolysisusing cadmium acetate as cadmium source and $\mathrm{H}_{2} \mathrm{~S}$ as sulfur source ${ }^{8}$. Many factors such as phase composition, crystallite size, morphology, specific surface area, band energy gap can influence the photocatalytic activity of CdS. Therefore, it is very important to study how to get the efficient CdS photocatalysts with different phase compositions and their photocatalytic activities by controlling reaction conditions.

In this study, the CdS nanocrystals with different phase compositions were synthesized by varying the reaction parameters. CdS nanoparticles were synthesized in aqueous medium at room temperature by simple chemical precipitation reactions. Four different reaction combinations were set to synthesize $\mathrm{CdS}$ nanoparticles. The effect of stabilizers on the stability and size of CdS nanoparticles was studied. The photocatalytic activities ofthe synthesized CdS nanoparticles for the degradation of acid blue-29 (AB-29) under visible light were also studied.

\section{Experimental}

All chemicals were of analytical grade and used as received without further purification. A stock solution of cadmium nitrate $\left(\mathrm{Cd}\left(\mathrm{NO}_{3}\right)_{2}\right)(0.09 \mathrm{M})$ was prepared and four different synthesis reactions were performed using methanol, ethanol and $0.2 \mathrm{M}$ 1-thioglycerol as stabilizers. $0.1 \mathrm{M}$ $\left(\mathrm{NH}_{4}\right)_{2} \mathrm{~S}$ was used as a source of $\mathrm{S}^{2-}$ ions. The reactions are summarized as below

\section{Reaction-I (Sample Code: $M-I$ )}

In a round bottom flask, to the $150 \mathrm{~mL}$ of $0.09 \mathrm{M}\left(\mathrm{Cd}\left(\mathrm{NO}_{3}\right)_{2}\right)$ solution, same quantity of $0.1 \mathrm{M}\left(\mathrm{NH}_{4}\right)_{2} \mathrm{~S}$ solution and $50 \mathrm{~mL}$ of $0.1 \mathrm{M} \mathrm{NaOH}$ solution was added separately with vigorous stirring. Stirring was continued for 4 hours. The dark yellow precipitates of $\mathrm{CdS}$ nanoparticles were obtained.

\section{Reaction-II (Sample Code: M-II)}

To the $150 \mathrm{~mL}$ of $0.09 \mathrm{M}\left(\mathrm{Cd}\left(\mathrm{NO}_{3}\right)_{2}\right)$ solution, $40 \mathrm{~mL}$ of methanol was added with continuous stirring for $30 \mathrm{~min} .150 \mathrm{~mL}$ of $0.1 \mathrm{M}\left(\mathrm{NH}_{4}\right)_{2} \mathrm{~S}$ solution and $50 \mathrm{~mL}$ of $0.1 \mathrm{M}$ $\mathrm{NaOH}$ solution was added and vigorous stirring was continued for additional 4 hours. A dark yellow solution was obtained as a result.

\section{Reaction-III (Sample Code: M-III)}

$0.1 \mathrm{M}\left(\mathrm{NH}_{4}\right)_{2} \mathrm{~S}$ solution, $50 \mathrm{~mL}$ of $0.1 \mathrm{M} \mathrm{NaOH}$ and $40 \mathrm{~mL}$ of ethanol was added drop wise to $150 \mathrm{~mL}$ of $0.09 \mathrm{M}\left(\mathrm{Cd}\left(\mathrm{NO}_{3}\right)_{2}\right)$ solution and vigorous stirring was continued for 4 hours and a faint yellow solution was obtained.

\section{Reaction-IV (Sample Code: M-IV)}

$150 \mathrm{~mL}$ of $0.2 \mathrm{M}$ 1-thioglycerol, $0.1 \mathrm{M}\left(\mathrm{NH}_{4}\right)_{2} \mathrm{~S}$ solution and $50 \mathrm{~mL}$ of $0.1 \mathrm{M} \mathrm{NaOH}$ was added slowly to $150 \mathrm{~mL}$ of $0.09 \mathrm{M}\left(\mathrm{Cd}\left(\mathrm{NO}_{3}\right)_{2}\right)$ solution and vigorous stirring was continued for 4 hours. As the formation of $\mathrm{CdS}$ started, the reaction system gradually changed from transparent to light yellow. 


\section{Characterization of synthesized $C d S$ nanoparticles}

The structural and morphological properties were studied by $\mathrm{x}$-ray diffraction (XRD) spectroscopy, x-ray diffractometer using Ni-filtered $\mathrm{Cu} \mathrm{K \alpha}$ radiation at scan range of $20-80^{\circ}$, scanning electron microscopy (SEM) and transmission electron microscopy (TEM).

\section{Photocatalytic activity}

The photocatalytic activity of the synthesized nanoparticles was studied by studying the photodecolorization of AB-29 in presence of visible light in a photoreactor made of Pyrex glass consisting of inner and outer jacket and equipped with a magnetic bar, a water circulating jacket and an opening for molecular oxygen. A halogen liner lamp $(500 \mathrm{~W})$ was used as a source of light. In presence of atmospheric oxygen $200 \mathrm{~mL}$ of $0.04 \mathrm{mM} \mathrm{AB}-29$ containing the appropriate quantity of the catalyst $\left(1 \mathrm{gL}^{-1}\right)$ was magnetically stirred in dark for at least 30 minutes to attain adsorption-desorption equilibrium between dye and catalyst surface. Temperature $\left(20 \pm 0.5^{\circ} \mathrm{C}\right)$ was maintained using circulating water bath and the suspensions were continuously purged with molecular oxygen throughout each experiment. The photo decolorization of AB-29 was monitored by the change in absorption using UV-Vis. spectroscopic analysis technique. The photocatalytic performances of the photocatalysts were studied for 4 consecutive cycles using the same portion of photocatalysts and a fresh solution of dye sample every time under similar conditions.

\section{Results and Discussion}

\section{$X$-ray diffraction studies}

The XRD pattern displayed in Figure 1 showed that the crystal structure of CdS nanoparticles changed from hexagonal (sample M-I) to cubic (samples M-II, M-III and M-IV) with the decrease in particle size. The diffraction peaks of the nanoparticles are considerably broadened due to the small size of the crystallites. The peaks can be indexed as (111), (200), (220) and (311) which are characteristic peaks of crystal planes for CdS cubic phase (Table 1). The crystallite size of the synthesized CdS (sample M-IV) nanoparticles was measured to be $3.24 \mathrm{~nm}$ according to Scherrer formula from the (111) plane.

$$
\mathrm{D}=\frac{\mathrm{k} \lambda}{B \cos \theta}
$$

Where $K$ is the wavelength of copper $K \alpha$ line $(1.5406 \AA), \theta$ is the angle between the incident beam and the reflection lattice planes, $B$ is full width half maximum of the peak and $\mathrm{D}$ is the average particle size $(\mathrm{nm})$.

Table 1. The crystalline phase, average crystallite size and pore size of synthesized CdS nanoparticles

\begin{tabular}{cccc}
\hline Sample code & Crystalline phase & $\begin{array}{c}\text { Average crystallite } \\
\text { size, } \mathrm{nm}\end{array}$ & $S_{\mathrm{BET}}, \mathrm{m}^{2} / \mathrm{g}$ \\
\hline M-I & Hexagonal and cubic & 29.62 & 117 \\
M-II & Hexagonal and cubic & 12.81 & 225 \\
M-III & Cubic & 6.57 & 324 \\
M-IV & Cubic & 3.24 & 378 \\
\hline
\end{tabular}



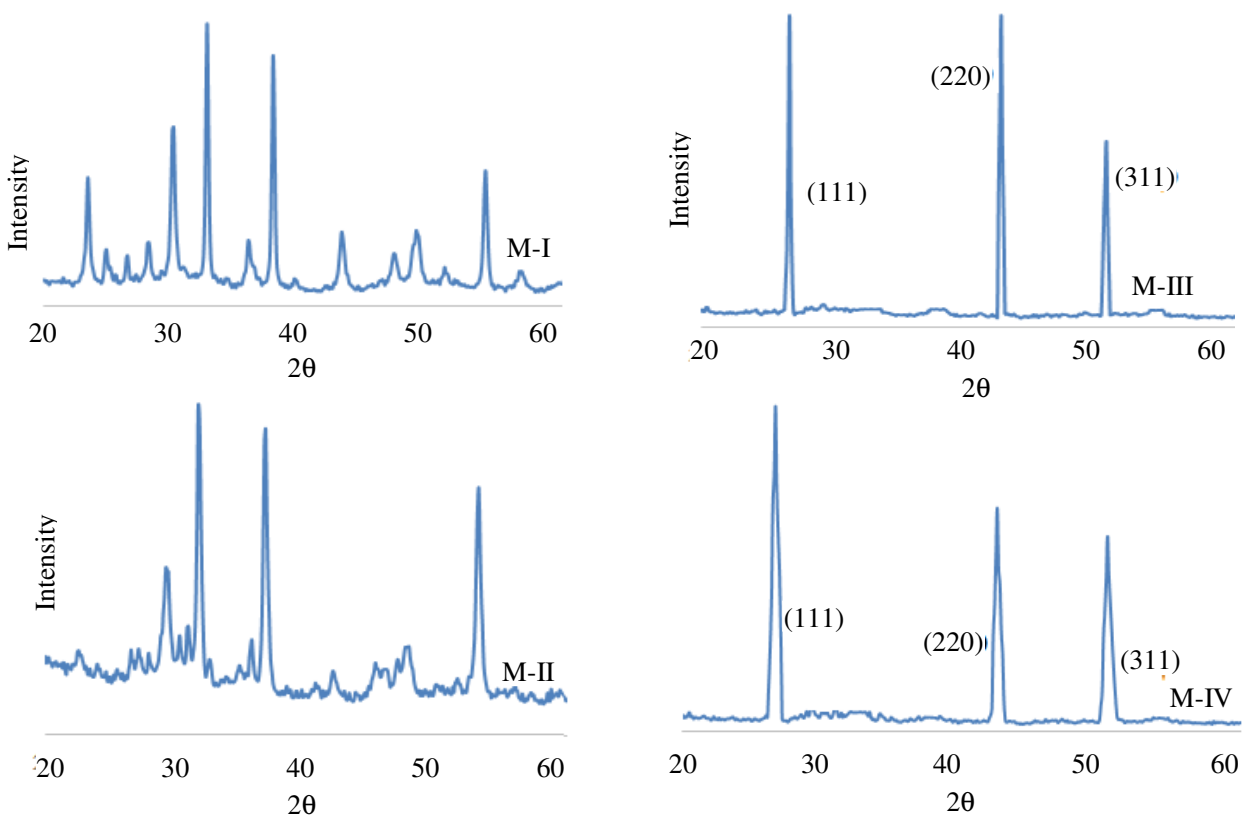

Figure 1. XRD pattern of synthesized CdS samples (M-I, M-II, M-III and M-IV)

\section{Scanning electron microscopy (SEM)}

The SEM images of CdS prepared by different methods, shown in Figure 2 revealed that the prepared catalyst samples were highly porous and aggregated. The surface morphology of the catalyst M-IV is quite different from the other samples prepared. The surfaces of the catalysts M-I, M-II and M-III appear to be agglomerates of granular particles and spiny surface can be visualized for the M-IV. The particle size of the mixed oxides is small and uniformly distributed.
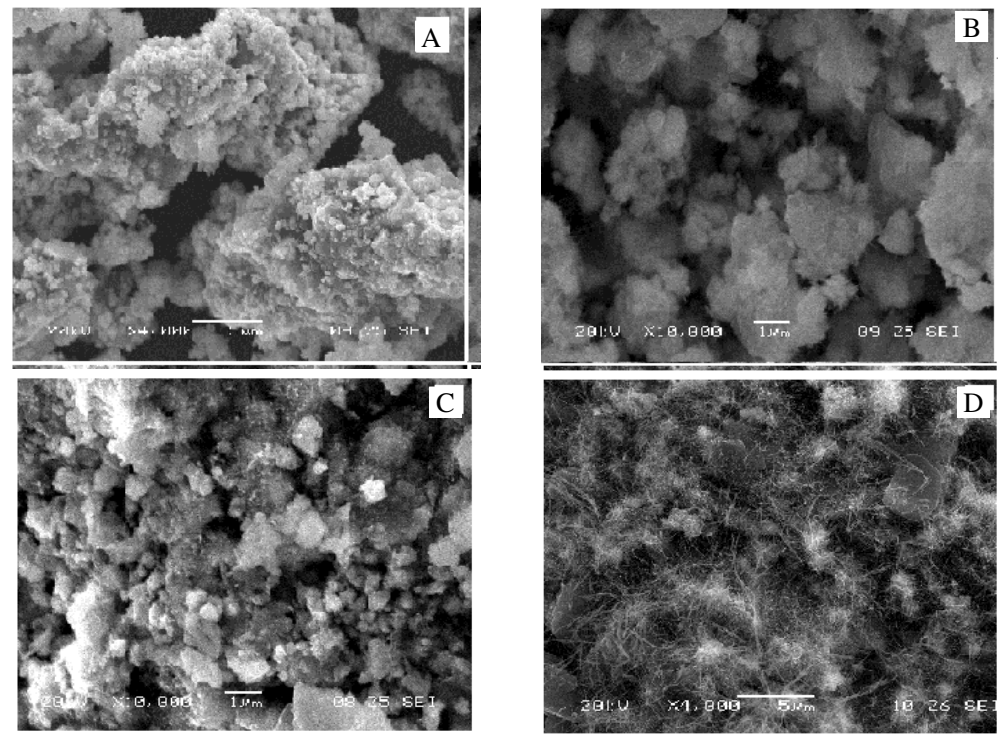

Figure 2. SEM images of sample (A) M-I, (B) M-II, (C) M-III and (D) M-IV 


\section{Transmission electron microscopy (TEM)}

The morphology of the sample investigated by transmission electron microscopy for M-IV is presented in Figure 3. The TEM image shows that the sample is composed of clusters of particles having well defined spherical morphology. The particle size distribution of the 35 selected particles of M-IV is shown in Figure 3.

\section{UV-Visible spectra}

Figure 4 shows UV-Visible absorption spectra of $\mathrm{CdS}$ nanoparticles synthesized by four different routes. The UV-Visible absorption spectra of the synthesized nanomaterials is in the region of $400-700 \mathrm{~nm}$ of solar spectrum. It is observed from the spectrum that the absorption onset edge is found to be at the lower wavelength corresponding to $412 \mathrm{~nm}$ indicating the blue shift in absorption edge. The blue shift of light absorption confirms the quantum confinement effect in the prepared nanosample and is highly agreed with the result of direct band gap (Table 2) semiconductor nanocrystals reported for potential applications ${ }^{9}$. The shift of the optical absorption towards lower wavelength also reveals the decreasing size of the nanoparticles.

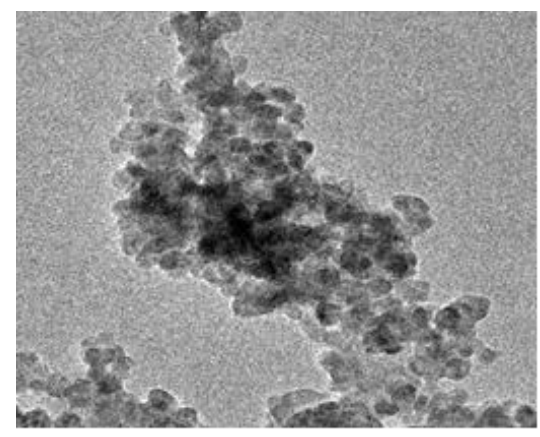

Figure 3. TEM image of sample M-IV

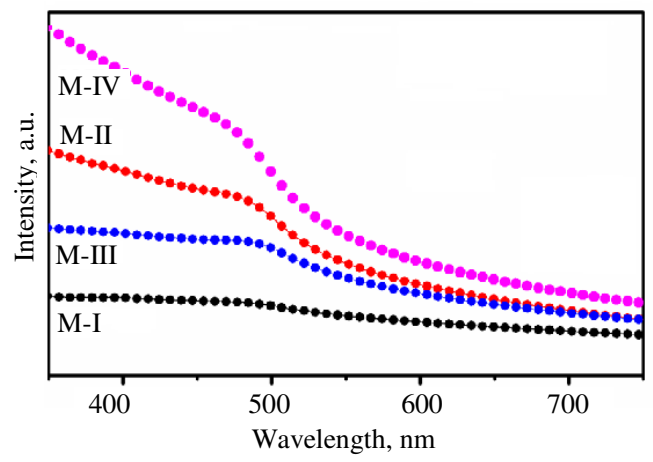

Figure 4. UV-Visible absorption spectra of CdS nanoparticles synthesized by different methods

Table 2. The band gap energy obtained from absorption spectra of synthesized CdS nanoparticles

\begin{tabular}{ccccc}
\hline CdS Nanoparticles & Sample M-I & Sample M-II & Sample M-III & Sample M-IV \\
\hline Absorption wavelength, nm & 465 & 452 & 434 & 412 \\
Band gap, eV & 2.66 & 2.74 & 2.85 & 3.0 \\
\hline
\end{tabular}

\section{Photocatalytic decomposition of acid blue 29}

The photocatalytic activities of CdS nanomaterials were evaluated by degradation of acid blue 29. The maximum UV-Vis absorbance of the dye was found to be $603 \mathrm{~nm}$. Thus the photocatalytic activity of CdS nanoparticles was investigated at $603 \mathrm{~nm}$ for the dye.

In photocatalytic treatment, $100 \mathrm{~mL}$ of reactant solution with an initial concentration of $2.5 \times 10^{-3} \mathrm{~mol} \mathrm{~L}^{-1}$ of acid blue 29 was treated with $0.2 \mathrm{~g}$ of catalyst samples. The concentration of the dye solution was determined by using a spectrophotometer operation in the visible range of absorbance. To achieve the adsorption/desorption equilibrium, the solution was kept for magnetic stirring in a dark environment for $30 \mathrm{~min}$. To determine the change in dye concentration in solution duringthe process, a few milliliters of the solution was taken from 
the reaction mixture at the same time interval, subsequently centrifuged, filtered through amillipore filter to separate the catalysts and loaded into a UV-Vis spectrometer. The photodegradation efficiency of acid blue 29 has been calculated by applying the following equation:

$$
\% \text { Photodegradation efficiency }=\frac{C o-C}{C o}
$$

Where $C_{o}$ is the original methylene blue content, $C$ is the retained acid blue 29 in solution. Figure 5 shows the effect of irradiation time and preparation method on photocatalytic oxidation of acid blue 29 . One can see that, the highest value of degradation was for sample M-IV in $25 \mathrm{~min}$. The variation in activity should be due to the differences in physical properties such as band gap, particle size and surface texture induced due to different preparation techniques.

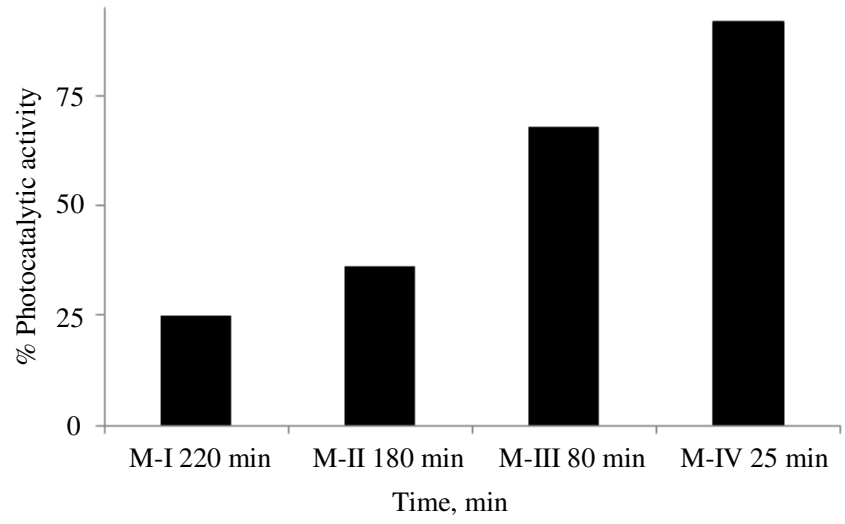

Figure 5. Effect of irradiation time and preparation method on photocalytic efficiency percentage of acid blue 29. (Catalyst $0.2 \mathrm{~g} / 100 \mathrm{~mL}$, dye concentration $2.5 \times 10^{-3} \mathrm{~mol} \mathrm{~L}^{-1}$ )

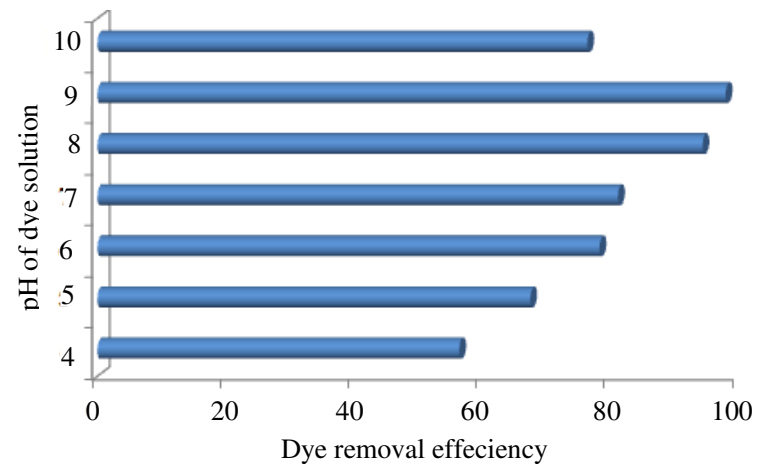

Figure 6. Effect of $\mathrm{pH}$ of dye solution on acid blue 29 removal efficiency using sample M-IV (Catalyst $0.2 \mathrm{~g} / 100 \mathrm{~mL}$, irradiation time $25 \mathrm{~min}$, dye concentration $2.5 \times 10^{-3} \mathrm{~mol} \mathrm{~L}^{-1}$ )

\section{Effect of $p H$}

A series of experiments has been carried out to study the effect of $\mathrm{pH}$ on acid blue 29 removal efficiency using sample M-IV (Figure 6). The findings are summarized in Table 3. From Figure 5, one can predict that increasing the $\mathrm{pH}$ of dye solution from 4 to 9 leads to an increase in dye removal efficiency from 45 to $96 \%$, but at $\mathrm{pH}$ more than 9 , the dye removal 
efficiency almost remains unchanged. The possible reason for this behavior is that at higher $\mathrm{pH}$ range, the presence of large quantity of $\mathrm{OH}^{-}$ions in the alkaline medium, favours the formation of $\cdot \mathrm{OH}$ radicals which enhances the photocatalytic degradation of dye significantly ${ }^{10}$. These $\mathrm{OH}^{-}$ions will generate more $\cdot \mathrm{OH}$ radicals by combining with the positive holes of the semiconductor. These hydroxyl radicals are responsible for degradation of dye $^{11}$. After a certain $\mathrm{pH}$ value i.e., above $\mathrm{pH}$ 9, the rate of photodegradation of acid blue 29 decreases due to coulombic repulsion between the negatively charged surface of photocatalyst and hydroxide anions. This fact could prevent the formation of hydroxyl radicals. This result into a decrease in the rate of photocatalytic degradation of dye ${ }^{12}$. The optimum condition for $\mathrm{pH}$ is 9 at which photodegradation percentage of acid blue 29 reach to $99 \%$.

Table 3. Effect of $\mathrm{pH}$ of dye solution on acid blue 29 removal efficiency using sample M-IV

\begin{tabular}{cc}
\hline $\begin{array}{c}\mathrm{pH} \text { of acid blue 29 dye } \\
\text { solution }\end{array}$ & $\begin{array}{c}\text { Acid blue 29 removal } \\
\text { Efficiency, \% }\end{array}$ \\
\hline 4 & 56.5 \\
5 & 67.6 \\
6 & 78.4 \\
7 & 81.3 \\
8 & 94.5 \\
9 & 98.1 \\
10 & 76.5 \\
\hline
\end{tabular}

\section{Effect of catalyst dose}

The amount of semiconductor powder may also affect the process of dye degradation. Keeping the dye concentration constant at $\mathrm{pH}$ 9, different amounts of sample M-IV varying from $0.20-1.0 \mathrm{~g} / 100 \mathrm{~mL}$ were used. It was observed that the rate of dye decomposition increases with increasing catalyst level up to $0.40 \mathrm{~g}$ and beyond this, the rate of reaction becomes almost constant (Figure 7). This may be due to the fact that, initially the increase in the amount of catalyst increases the numberof active sites on the surface that in turn increases the number of - $\mathrm{OH}$ and $\mathrm{O}_{2}{ }^{--}$radicals leading to an increase in degradation rate. Above $0.4 \mathrm{~g}$, the number of substrate molecules isnot sufficient to fill the active sites of $\mathrm{CdS}$ and increase in turbidity of solution reduces the light transmission through the solution. Hence, further addition of catalyst does not lead to the enhancement of the degradation rate and it remains constant ${ }^{13}$.

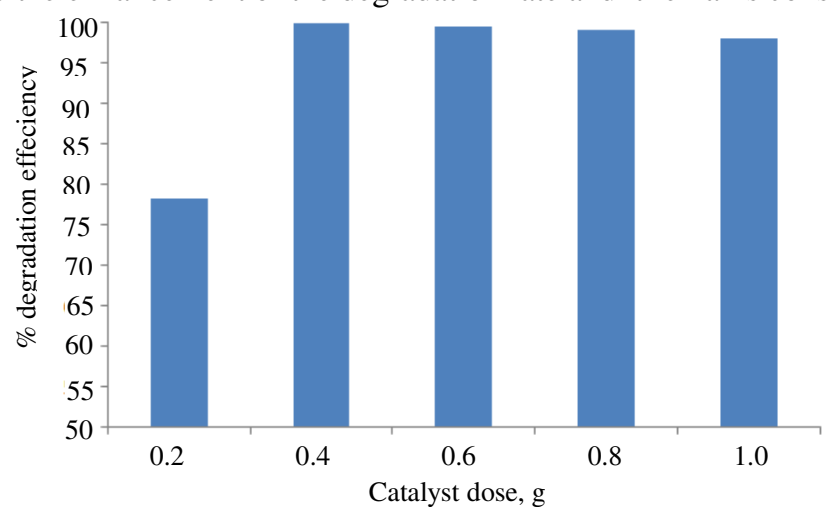

Figure 7. Effect of catalyst dose on acid blue 29 removal efficiency using sample M-IV (pH of dye solution 9 , irradiation time $10 \mathrm{~min}$, dye concentration $2.5 \times 10^{-3} \mathrm{~mol} \mathrm{~L}^{-1}$ ) 


\section{Conclusion}

CdS nanoparticles were synthesized via chemical precipitation method, using $\left(\left(\mathrm{NH}_{4}\right)_{2} \mathrm{~S}\right.$ as a source of $\mathrm{S}^{2-}$ ions in the presence and absence of stabilizing agents. Four different reaction combinations were set to synthesize CdS nanoparticles. The stabilizing agent affected the nanoparticles size and prevented the agglomeration of nanoparticles. The synthesized nanomaterials showed fine elemental purity, quantum size effect and anincrease in band gap with the decrease in particle size. With respect to the bulk CdS, all the synthesized CdS nanoparticles showed considerable blue shift in absorption edge. The presence of hexagonal and cubic phases indicates the crystalline nature of samples. The average particles sizes obtained by XRD, SEM and TEM were found to be in good agreement with each other and were in the range 3-29 $\mathrm{nm}$. The photocatalytic activities of the synthesized CdS nanoparticles for the degradation of acid blue-29 (AB-29) under visible light were also studied. The rate of degradation was found to increase with the decrease in particle sizes. But, the stability of the $\mathrm{CdS}$ nanoparticles decreased with time after consecutive degradation cycles. This might be due to the photocorrosion of CdS. The results obtained in the study can be useful and helpful in designing an up scalable, practical process for dye wastewater treatment.

\section{Acknowledgement}

The financial support of this work by University Grant Commission, New Delhi is gratefully acknowledged. Also, the authors thank the Department of Physics, Vidyabharti Mahavidyalaya Amravati, M. S. India for providing the x-ray diffraction facility and the Department of Physics, Pune University, Pune, M.S. India, for providing the scanning electron microscope (SEM) measurement.

\section{References}

1. Yu J G, Jaroniec M and Lu G X, Int J Photoenergy, 2012, 5; DOI:10.1155/2012/206183

2. Xiang Q J, Yu J G and Jaroniec M, Chem Soc Rev., 2012, 41, 782-796; DOI:10.1039/C1CS15172J

3. Xiang Q J, Yu J G and Jaroniec M, J Am Chem Soc., 2012, 134(15), 6575-6578; DOI:10.1021/ja302846n

4. Zhou X M, Liu G, Yu J G and Fan W H, J Mater Chem., 2012, 22, 21337-21354; DOI:10.1039/C2JM31902K

5. Sahu N, Arora M K, Upadhyay S N and Sinha A S K, Ind Engg Chem Res., 1998, 37(12), 4682-4688; DOI:10.1021/ie980237s

6. Lin G, Zheng J and Xu R, J Physical Chem C, 2008, 112(19), 7363-7370; DOI:10.1021/jp8006969

7. Bao N, Shen L, Takata T, Domen K, Gupta A, Yanagisawa K and Grimes C A, $J$ Phys Chem C, 2007, 111(47), 17527-17534; DOI:10.1021/jp076566s

8. Jing D and Guo L, J Phys Chem B, 2006, 110(23), 11139-11145; DOI:10.1021/jp060905k

9. Irimpan L, Nampoori V P N and Radhakrishnan P V P N, J Appl Phys., 2008, 103, 094914; DOI:10.1063/1.2919109

10. Liu S F, Abothu I R and Komarneni S, Mater Lett., 1999, 38(5), 344-350; DOI:10.1016/S0167-577X(98)00187-6

11. Faisal M, Tariq M A and Muneer M, Dyes and Pigments, 2007, 72(2), 233-239; DOI:10.1016/j.dyepig.2005.08.020 
12. Sauer T, Neto G C, Jose H J and Moreira R F P M, J Photochemistry Photobiology A. Chemistry, 2002, 149(1-3), 147-154; DOI:10.1016/S1010-6030(02)00015-1

13. Mrowetz M, Pirola C and Selli E, Ultrasonics Sonochem, 2003, 10(4-5), 247-254; DOI:10.1016/S1350-4177(03)00090-7 